\title{
Asperosaponin VI promotes human mesenchymal stem cell differentiation into nucleus pulposus like- cells via up-regulation of ERK1/2 and Smad2/3 signaling pathways.
}

\section{Yong-Tao Niu}

Nanjing University of Chinese Medicine

Lin Xie ( $D$ xielin6508@163.com )

Jiangsu Province Academy of Traditional Chinese Medicine https://orcid.org/0000-0001-6821-6375

\section{Rong-Rong Deng}

Nanjing University of Chinese Medicine

Xiao-Yu Zhang

Nanjing University of Chinese Medicine

Research

Keywords: Asperosaponin VI, Human mesenchymal stem cell, Differentiation, Nucleus pulposus like- cells , ERK1/2 and Smad2/3

Posted Date: May 19th, 2020

DOI: https://doi.org/10.21203/rs.3.rs-27853/v1

License: (c) (i) This work is licensed under a Creative Commons Attribution 4.0 International License.

Read Full License 


\section{Abstract \\ Background}

At present, the regeneration of nucleus pulposus cells is an effective method to prevent intervertebral disc degeneration (IVDD). In this study, we investigated the role of Asperosaponin VI (ASA VI), isolated from a traditional Chinese medicine (TCM), the root of Dipsacus asper Wall, in promoting human mesenchymal stem cell (HMSC) proliferation and differentiation into nucleus pulposus like-cells and explored its possible mechanism of action.

\section{Methods}

First, the effects of ASA VI on HMSC vitality and proliferation were determined by the XTT method and EDU staining. Then, HMSCs were cultured with ASA VI. Real-time PCR, immunocytochemistry and immunofluorescence were used to measure the expression of extracellular matrix (ECM) components in nucleus pulposus cells, such as type II collagen(COL2A1), aggrecan, SOX9, KRT19, PAX1 and glycosaminoglycans (GAGs), and Western blot was used to investigate its potential mechanism.

\section{Results}

ASA VI could promote HMSC differentiation into nucleus pulposus like-cells, and its optimum concentration was $1 \mathrm{mg} / \mathrm{L}$. The Western blot assays indicated that the possible mechanisms involved upregulating the expression of P-ERK1/2 and P-Smad2/3.

\section{Conclusions}

ASA VI can promote HMSC proliferation and differentiation into nucleus pulposus like-cells, which can be used as a potential treatment for IVDD.

\section{Background}

Low back pain (LBP) is a common disease, and approximately $80 \%$ of the general population experience it at least once in their lives[1]. IVDD is related to age, load-bearing labor, trauma and heredity and leads to chronic low back pain and economic burden[2]. Although there are many factors that can lead to LBP, IVDD is considered as a major factor[3,4]. Treatment of IVDD remains a clinical challenge due to conservative treatment, in which only symptoms can be alleviated, while surgical treatment leads to complications and structural damage[5]. Thus, there is no approved program for the treatment of degenerative intervertebral discs; therefore, it is very important to find a treatment for the etiology of IVDD. 
The intervertebral disc(IVD) is mainly composed of cartilage tissue, including nucleus pulposus, annulus fibrous and endplates. Some studies have shown that the changes of ECM biosynthesis and the decreases in nucleus pulposus cell function and number are the primary factors of IVDD[6]. Therefore, increasing extracellular matrix and promoting the regeneration of NP cells have become an ideal treatment. Due to poor regeneration of NP cells, cell-based therapy may be a promising treatment for IVDD[7]. At present, increasing amounts of attention have been paid to using the multidirectional differentiation potential of stem cells to promote the regeneration of degenerative IVD[8].

Moreover, a large number of experimental studies have confirmed that stem cell applications are effective treatments with great clinical application potential[$[9,10]$. There are many research methods to promote the differentiation of stem cells into nucleus pulposus for the treatment of degenerative IVD, including growth factor intervention, coculture of stem cells and nucleus pulposus cells, hypoxia induction, stem cells planted in three-dimensional scaffolds, and applied stress, which promote the differentiation of stem cells into nucleus pulposus-like cells to a certain extent[11-15]. However, it is rare to use traditional Chinese medicine to promote the differentiation of stem cells into nucleus pulposus-like cells to repair a degenerative IVD.

Asperosaponin VI (ASA VI), also known as Akebia Saponin D(ASD), is the main bioactive component of the traditional Chinese medicine (TCM) Radix Dipsaci. The Chinese Pharmacopoeia specifies ASA VI content as Dipsacus asper Wall quality standard.

Dipsacus asper Wall, as an herbal medicine, has the effect of tonifying the liver and kidney, with a long history of safe use for strengthening the tendons and bones. The study found that Radix Dipsaci functions by inhibiting osteoclast differentiation, preventing osteoporosis and promoting fracture healing[16-18]. In addition, Radix Dipsaci can upregulate the expression of TGF- $\beta 1$, increase collagen formation and promote Achilles tendon healing[19]. It has not yet been reported that ASA VI can promote the differentiation of stem cells into nucleus pulposus-like cells.

Numerous signaling pathways are regulated by the function of ASA VI, including PI3K/AKT, HIF-1a/VEGF, P38, and ERK1/2[20-22]. The mechanism by which ASA VI promotes the differentiation of stem cells into nucleus pulposus-like cells remains to be further studied. In this study, we evaluated how ASA VI affects the proliferation of stem cells and its possible potential mechanism of promoting the differentiation of HMSCs into nucleus pulposus-like cells.

\section{Materials And Methods}

\section{Materials}

ASA VI was purchased from Chengdu Must Bio-Technology Co. Ltd. (purity $>99 \%$, China). Mesenchymal Stem Cell medium (MSCm) (Sciencell, 7501, USA), fetal bovine serum (FBS, Sciencell, 7552, USA) and dulbecco's phosphate buffered saline(DPBS, Sciencell, 0303, USA) were purchased from Sciencell. DMEM/F12 (Gibco, 21041025, USA) was purchased from Gibco. BeyoClick EdU-488 (Beyotime, C0071S, 
China) was purchased from Beyotime Institute of Bio-Technology Co. Ltd. ProtoScript II cDNA (NEB, m3003L, USA) was purchased from NEB. DAPI (Sigma-Aldrich, D9542, USA), dimethylmethylene blue (Sigma-Aldrich, 341088, USA), glycine (Sigma-Aldrich, 410225, USA), glacial acetic acid (Sigma-Aldrich, S7653, USA) and bovine chondroitin 4-sulfate as standard (Sigma-Aldrich, C9819, USA) were purchased from Sigma-Aldrich. Primary antibodies for $\beta$-catenin (abcam, ab179467, USA) and paxillin1

(PAX1,abcam, ab32084, USA) were purchased from abcam. Aggrecan (Proteintech, 13880-1-AP, USA) was purchased from Proteintech, and Smad2/3 (Cell Signaling, 8685T, USA), phospho-Smad2/3 (Cell Signaling, 8828S, USA), ERK1/2 (Cell Signaling, 4695T, USA), and phospho-Erk1/2 (Cell Signaling, 4370T, USA) were purchased from Cell Signaling. Anti-rabbit secondary antibodies (abcam, ab150077, USA) were purchased from abcam.

\section{Cell culture}

Human mesenchymal stem cells (HMSCs) (Sciencell, 7500, USA) were purchased from Sciencell. Primary HMSCs were obtained by digestion. The cell line was cultured in mesenchymal stem cell medium (MSCm), supplemented with $10 \% \mathrm{FBS}, 1 \%$ penicillin and $1 \%$ streptomycin at $37^{\circ} \mathrm{C}$ in a humidified atmosphere of $5 \% \mathrm{CO}_{2}$ in a T-75 flask for 48 hours before the first medium change. At $80 \%$ confluence, the cells were trypsinized ( $0.25 \%$ trypsin-EDTA) and passaged into T-25 flasks at a ratio of 1:3. HMSCs from the sixth passage were used in all experiments. For all subsequent experiments except the cell vitality and proliferation assays, the cultured medium was replaced with DMEM/F12 supplemented with FBS (Invitrogen, 1600044, USA), dexamethasone (Sigma-Aldrich, D1756, USA), ascorbic acid-2-phosphate (Sigma-Aldrich, A4544, USA) L-proline (Sigma-Aldrich, P0380, USA), ITS Supplement (Cyagen Biosciences Company, 10201, USA), and TGF- $\beta 1$ (PeproTech, 96-100-21-10, USA).

\section{Assessment of cellular vitality}

Cell vitality was evaluated by cell counting XTT assays (Sigma-Aldrich, X4626, USA) according to the manufacturer's instructions. In brief, HMSCs were seeded on 96 -well plates $\left(2 \times 10^{3}\right.$ cells $/$ well $)$ at $37^{\circ} \mathrm{C}$ in a humidified atmosphere of $5 \% \mathrm{CO}_{2}$ for 24 hours. Then, $50 \mu$ of XTT testing work fluid was added to each well, and the plates were cultured at $37^{\circ} \mathrm{C}$ in a humidified atmosphere of $5 \% \mathrm{CO}_{2}$ for 4 hours. After that, cells were treated with different concentrations of ASA VI $(0,0.01,0.1,1,10$, and $100 \mathrm{mg} / \mathrm{l})$, the MSCm and ASA VI were changed every 72 hours, $50 \mu$ of XTT test working solution was added to each well, and the plates were cultured at $37^{\circ} \mathrm{C}$ in a humidified atmosphere of $5 \% \mathrm{CO}_{2}$ for 4 hours after 1,3 and 5 days. The absorbance was measured at $450 \mathrm{~nm}$ using a microplate reader (Bio Tek, USA) after each addition of XTT test working solution.

\section{Assessment of cellular proliferation}

Cell proliferation was assessed by an EDU test using a BeyoClick EdU-488 cell proliferation kit combined with DAPI staining according to the manufacturer's instructions. The HMSCs were plated on 96-well plates $\left(2 \times 10^{3}\right.$ cells/well $)$ at $37^{\circ} \mathrm{C}$ in a humidified atmosphere of $5 \% \mathrm{CO}_{2}$ for 24 hours. Then, different doses of ASA VI $(0,0.01,0.1$, and $1 \mathrm{mg} / \mathrm{L})$ were added to the wells, and the MSCm and ASA VI were 
changed every 72 hours. Five days later, the EDU reagent $(0.5 \mu \mathrm{L}, 50 \mu \mathrm{mol} / \mathrm{L})$ was added into each well containing $200 \mu \mathrm{L}$ of $\mathrm{MSCm}$ and incubated at $37^{\circ} \mathrm{C}$ in a humidified atmosphere of $5 \% \mathrm{CO}_{2}$. for 2 hours. Then, cells were fixed with $4 \%$ paraformaldehyde and incubated with amino acetic acid for 5 minutes. After that, $100 \mu \mathrm{L}$ of penetrant was added to each well and incubated for 5 minutes. Then, each well was supplemented with $100 \mu \mathrm{L}$ of 1 xEDU work fluid, and 30 minutes later, DAPI was used to stain cell nuclei for 10 minutes[23]. The stained cells were observed under a fluorescence microscope (OLYMPUS, USA).

\section{Quantitatie Real-time Polymerase Chain Reaction}

The HMSCs were plated on 6-well dishes. Then, cells were treated with different concentrations of ASA VI $(0,0.01,0.1,1,10$, and $100 \mathrm{mg} / \mathrm{L})$. The mixture was changed every 72 hours. Total RNA was extracted from cells after 3 and 7 days using TRIzol reagent (INV, 15596026, USA) according to the manufacturer's instructions. Then, $c D N A$ was synthesized by applying a cDNA reverse transcription kit according to the manufacturer's instructions. In brief, first, an 8- $\mu \mathrm{L}$ reaction mixture containing $1 \mu \mathrm{g}$ of total RNA, $2 \mu \mathrm{L}$ of oligo $d(T) 23 V N(50 \mu M)$ and RNase-free $\mathrm{dH}_{2} \mathrm{O}$ was incubated at $65^{\circ} \mathrm{C}$ for 5 minutes. Subsequently, $10 \mu \mathrm{L}$ of ProtoScript II Reaction Mix (2X) and $2 \mu \mathrm{L}$ of Proto-Script II Enzyme Mix (10X) were added to a final volume of $20 \mu \mathrm{L}$, and the mixture was incubated at $42{ }^{\circ} \mathrm{C}$ for 60 minutes. Finally, the mixture was incubated at $80^{\circ} \mathrm{C}$ for 5 minutes. Gene expression was analyzed by quantitative real-time polymerase chain reaction( PCR, ABI Stepone Plus, USA). GAPDH was used to quantify PCR products and to confirm the use of equivalent RNA. Reactions were carried out in duplicate in a 96-well plate with a final volume of $20 \mu \mathrm{L}$. The PCR included an initial enzyme activation stage at $95^{\circ} \mathrm{C}$ for 10 minutes, followed by 40 cycles of $95^{\circ} \mathrm{C}$ for $15 \mathrm{~s}$ and $60^{\circ} \mathrm{C}$ for $60 \mathrm{~s}$. Products were quantified using a melting curve analysis. Results were calculated using the $2^{-\Delta \Delta c t}$ method. The primers used in this study are shown in table 1 .

\section{Glycosaminoglycans (GAGs) assay}

The HMSCs were plated on 6-well plates. After 24 hours, cells were treated with the appropriate concentration of ASA VI (1 mg/L), while cells in the control group were not treated with ASA VI. The medium was changed every 72 hours. To investigate the effect of ASA VI on the secreted ECM proteins, a dimethylmethylene blue assay (DMMB) was used to quantify the soluble GAGs in the cell culture media. After 7 and 14 days, the cell culture media were collected. A portion of the media was mixed with DMMB dye and incubated with moderate agitation at room temperature for 30 minutes. Upon incubation, the solution was centrifuged to form a pellet of GAGs that bound to the dye. The pellet was washed in icecold acid-salt solution, centrifuged and resuspended in 10\% SDS for the DMMB assay. The DMMB assay was quantified at $525 \mathrm{~nm}$ using a microplate reader (Bio Tek, USA). Absorbance was converted to GAG concentrations using a calibration curve obtained using different concentrations of bovine chondroitin 4sulfate as the standard. The GAGs were normalized using the total protein in the media quantified at UV $280 \mathrm{~nm}$ using a microplate reader (Bio Tek, USA)[24].

\section{Immunofluorescence staining}


The HMSCs were plated on 96 -well plates $\left(2 \times 10^{3}\right.$ cells/well) at $37^{\circ} \mathrm{C}$ in a humidified atmosphere of $5 \%$ $\mathrm{CO}_{2}$ for 24 hours. Then, cells were treated with the appropriate concentration of ASA VI (1 mg/L), while control cells were not treated with ASA VI. The medium was changed every 72 hours. After 14 days, cells were fixed with $4 \%$ paraformaldehyde for 5 minutes. After that, each well was treated with $0.2 \%$ Triton X100 in 1X PBS for 5 minutes at room temperature. Cells were then blocked with $5 \%$ blocking serum from specific species in 1X PBS at room temperature for 1 hour. Subsequently, cells were incubated with primary antibody (1:50) diluted in antibody dilution buffer for 1 hour at room temperature, followed by incubation with the corresponding fluorochrome-labeled secondary antibodies diluted in antibody dilution buffer (1:200) for 1 hour at room temperature in the dark. Finally, DAPI was used to stain cell nuclei for 10 minutes[25]. The stained cells were observed under a fluorescence microscope (OLYMPUS, USA).

\section{Western blotting analysis}

The HMSCs were plated on 6-well plates. After 24 hours, cells were treated with the appropriate concentration of ASA VI ( $1 \mathrm{mg} / \mathrm{L})$, while control cells were not treated with ASA VI. After 48 hours, cells were washed with PBS and lysed with lysis buffer mixed with PMSF for 30 minutes on the ice, followed by ultrasonic fragmentation (400W, Ultrasound 15 seconds, stop 15 seconds) for 10 minutes on an ice bath. After centrifuging for 10 minutes at $10,000 \times$ g and $4{ }^{\circ} \mathrm{C}$, the soluble was added with Loading Buffer(5:1) and Boiled in boiling water for 5 minutes. Protein samples were separated by 10\% SDS-PAGE under $80 \mathrm{~V}$ for 30 minutes and $100 \mathrm{~V}$ for 90 minutes and then transferred to nitrocellulose membranes. The membranes were blocked with TBS buffer for 1 hour at room temperature. The primary antibodies (rabbit polyclonal anti-ERK1/2, anti-phosphospecific ERK1/2, anti-Smad2/3, anti-phosphospecific Smad2/3, 1/500 dilution; rabbit monoclonal anti- $\beta$-actin, 1/5000 dilution) were added to the nitrocellulose membranes and incubated overnight at $4{ }^{\circ} \mathrm{C}$.Subsequently, the membranes were washed thrice for 5 minutes each with TBS buffer and incubated with anti-rabbit secondary antibodies (1:5000) for 1 hour at room temperature. The membranes were washed thrice for 5 minutes each again, and detection was performed using a dual-color infrared imaging system (Odyssey, LI-COR,USA).

\section{Statistical analysis}

The results are expressed as the mean \pm standard deviation. Statistical significance was determined using a one-way ANOVA test and a T-test to compare the different groups in SPSS 19.0 statistical software. For each test, at least three independent parallel experiments were performed. $P<0.05$ was considered to be statistically significant.

\section{Results}

\section{Effect of ASA VI on HMSC proliferation}

The effect of ASA VI on the cell proliferation of HMSCs was evaluated by the XTT and EDU assays. Cell numbers were increased after incubation with different concentrations of ASA VI $(0.01,0.1,1,10$, and $100 \mathrm{mg} / \mathrm{L}$ ) for 1,3 and 5 days and peaked at $1 \mathrm{mg} / \mathrm{mL}$ (Fig. 1A ). The EDU assay results showed that the 
proliferation of HMSCs can be enhanced with the increase of ASA VI dose (Fig. 1B and 1C), which was similar to the XTT results.

\section{Nucleus Pulposus Cells Gene Expression under Different Concentrations of ASA VI}

To study the effects of different concentrations of ASA VI on the biosynthesis of HMSCs, ECM expression was analyzed by RT-PCR. The gene expression profiles were investigated after 3 and 7 days of ASA VI cultivation at 0 (control), $0.01,0.1,1,10$ and $100 \mathrm{mg} / \mathrm{L}$. Figure 2 shows the relative gene expression of the nucleus pulposus markers (type Il collagen, aggrecan, SOX9, KRT19, and PAX1) for the ASA VI and control groups. The results showed that the concentrations of $0.01,0.1$ and $1 \mathrm{mg} / \mathrm{l}$ ASA VI upregulated the gene expression levels of the markers, which peaked at $1 \mathrm{mg} / \mathrm{L}$. However, when the concentration of ASA VI increased to $10 \mathrm{mg} / \mathrm{l}$ and $100 \mathrm{mg} / \mathrm{l}$, the gene expression did not upregulate with the increased concentration and even appeared to be inhibited.

These findings indicated that $1 \mathrm{mg} / \mathrm{L}$ was the optimal concentration of ASA VI for stimulating HMSCs differentiation into nucleus pulposus like-cells. Thus, we adopted this concentration for the subsequent experiments.

\section{GAGs expression under ASA VI}

GAGs expression levels were investigated after 7 and 14 days of ASA VI cultivation at 0 (control) and $1 \mathrm{mg} / \mathrm{l}$. Figure 3 shows that the GAGs contents in the cell supernatants significantly increased with time in the experimental and control groups. The increase in the rate of GAGs contents in the cell supernatant of the experimental group was higher than that of the control group at 7 and 14 days.

\section{ASA VI accelerated aggrecan and PAX1 deposition}

Aggrecan and PAX1 immunofluorescence staining revealed stronger green staining in ASA VI (1 mg/l)treated groups compared with the control groups after being cultured for 14 days, which suggests that there was more abundant regenerated aggrecan and PAX1 deposition (Fig. 4).

\section{ASA VI upregulated P-ERK1/2 and P-Smad2/3 expression}

To investigate the mechanism of action of ASA VI in promoting the differentiation of HMSCs into nucleus pulposus like-cells, we explored the effect of ASA VI on P-Smad2/3 and P-ERK1/2 expression using Western blotting. The results indicated that ASA VI ( $1 \mathrm{mg} / \mathrm{l})$ could better upregulate both P-Smad2/3 and P-ERK1/2 protein levels than in the control group (Fig. 5 ).

\section{Discussion}


Due to the increasing aging of the population, the incidence of degenerative IVD is becoming higher and higher, and the treatment of degenerative IVD has received wide attention. Compared with traditional therapies, biotherapy may be more beneficial to relieve pain, repair degenerative nucleus pulposus and restore the biomechanical function of IVD[26]. Stem cells with high-efficiency self-renewal and pluripotency can be differentiated into various cell lines, including cartilage cell-like cells and nucleus pulposus-like cells. Therefore, inducing stem cells to differentiate into nucleus pulposus-like cells for IVDD has become the focus of biotherapy for IVDD. How to induce stem cells to differentiate into nucleus pulposus phenotype more effectively becomes a key problem in the treatment of IVDD[27]. Promoting the phenotypic differentiation of stem cells into nucleus pulposus cells is the basis of nucleus pulposus regeneration.

At present, there is no specific cell phenotype to identify nucleus pulposus cells. By comparing the phenotypes of cartilage cells and nucleus pulposus cells, it was found that type II collagen, aggrecan and SOX9 expression was shared by nucleus pulposus cells and cartilage cells[28, 29]. However, nucleus pulposus cells are significantly different from chondrocyte cells in terms of composition and biological function. Thus, to ensure the accumulation of proper ECM, it is necessary to identify the cell phenotype of differentiated cells. KRT19 as a specific marker of human chordae was used to identify positive markers in nucleus pulposus cells[30]. Thorpe AA et al have found that KRT19 can be used as a unique gene for the identification of nucleus pulposus cells[31]. PAX1 is involved in the regulation of IVD formation in the embryonic stage and has been verified in human nucleus pulposus cells. Moreover, it is widely used as a new positive phenotype for the identification of nucleus pulposus cells in the study of stem cell differentiation into nucleus pulposus[32]. Thus, genes such as type Il collagen, aggrecan, SOX9, KRT19 and PAX1 can be used as a genetic phenotype to identify nucleus pulposus cells.

As the main bioactive component of the Radix Dipsaci, previous studies have shown that ASA VI has the effects of protecting the nerves, heart, and liver and resisting osteoporosis[33]. In recent years, it has been reported that ASA VI has the effects of regulating intestinal microflora, preventing atherosclerosis, resisting inflammation, reducing cortisol, and promoting angiogenesis and wound healing[20, 34-37]. In this study, we found that compared with the control group, ASA VI had more potential to promote differentiation of HMSCs into nucleus pulposus-like cells, especially when the concentration of ASA VI was $1 \mathrm{mg} / \mathrm{L}$. To better understand the possible mechanism of ASA VI promoting differentiation of HMSCs into nucleus pulposus-like cells, we studied its effects on the ERK $1 / 2$ and Smad2/3 signaling pathways. Previous studies have found that the ERK and Smad signaling pathways are involved in the proliferation and differentiation of stem cells[38-40]. Moreover, in recent years, it has been found that the ERK1/2 and Smad2/3 signaling pathways regulate the differentiation of stem cells into nucleus pulposus-like cells and cartilage cell-like cells[41-42]. In this study, we found that ASA VI may promote the differentiation of HMSCs into nucleus pulposus cells by upregulation of P-ERK1/2 and P-smad2/3. However, the exact mechanism remains to be further verified.

\section{Conclusions}


We found that ASA VI promoted the differentiation of HMSCs into nucleus pulposus-like cells, probably by activating ERK1/2 and Smad2/3 signaling pathways. Our research increases our understanding of the potential mechanism of ASA VI promoting the differentiation of HMSCs into nucleus pulposus-like cells and suggests that ASA VI has therapeutic potential in the treatment of IVDD with stem cells.

\section{Abbreviations}

IVD

intervertebral disc

IVDD

intervertebral disc degeneration

ASA VI

Asperosaponin VI

TCM

traditional Chinese medicine

HMSC

human mesenchymal stem cell

XTT

2,3-bis-(2-methoxy-4-nitro-5-sulfophenyl)-2 h-tetrazolium-5-carboxanilide

EDU

5-ethynyl-2-deoxyuridine

COL2A1

type Il collagen

SOX9

sry-related high mobility group-box gene9

PAX1

paxillin1

KRT19

cytokeratin19

GAGs

glycosaminoglycans

ERK

extracellular regulated protein kinases

Smad

small mothers against decapentaplegic

LBP

Low back pain

ECM

extracellular matrix

IVD 
intervertebral disc

PI3K

phosphatidylinositol 3 kinase

AKT

protein kinase $B$

HIF-1a

hypoxia-inducible factor 1-alpha

VEGF

vascular endothelial growth factor

P38

protein 38

$\mathrm{MSCm}$

Mesenchymal Stem Cell medium

FBS

fetal bovine serum

PBS

phosphate buffered saline

DPBS

dulbecco's phosphate buffered saline

DMEM

dulbecco's modification of eagle's medium

DAPI

4,6-diamino-2-phenyl indole

EDTA

ethylene diamine tetraacetic acid

TGF- $\beta 1$

transforming growth factor-beta 1

PCR

polymerase chain reaction

RNA

ribonucleic acid

DNA

deoxyribonucleic acid

GAPDH

glyceraldehyde-3-phosphate dehydrogenase

DMMB

dimethylmethylene blue assay

PMSF

phenylmethanesulfonyl fluoride

SDS 
sodium dodecyl sulfate

SDS-PAGE

sodium dodecyl sulfate -polyacrylamide gel electrophoresis

\section{Declarations}

\section{Ethics approval and consent to participate}

Not applicable.

\section{Consent for publication}

All authors have provided consent for publication in the Journal of Chinese Medicine.

\section{Availability of data and materials}

The datasets used and/or analyzed during the current study are available from the corresponding author on reasonable request.

\section{Competing interests}

The authors declare that they have no competing interests.

\section{Funding}

This study was funded by the Foundation for leading talent in traditional Chinese medicine of Jiangsu province (2018SLJ0210)

\section{Authors' contributions}

YN conducted the study and drafted the manuscript. LX supervised the study and revised the manuscript. $\mathrm{RD}$ and $\mathrm{XZ}$ provided the technical support and advices for the study. all authors read and approved the final manuscript. 


\section{Acknowledgements}

We thank AJE (http://www.aje.com) for linguistic assistance during the preparation of this manuscript.

\section{References}

1. Lively MW.Sports medicine approach to low back pain[J].South Med J. 2002 Jun;95(6):642-6.

2. Waddell G.Low back pain: a twentieth century health care enigma.Spine (Phila Pa 1976)[J]. 1996 Dec 15;21(24):2820-5.

3. Manek NJ,MacGregor AJ.Epidemiology of back disorders: prevalence, risk factors, and prognosis.Curr Opin Rheumatol[J]. 2005 Mar;17(2):134-40.

4. Thompson K, Moore S, Tang S,et al.The chondrodystrophic dog: A clinically relevant intermediatesized animal model for the study of intervertebral disc-associated spinal pain[J].JOR Spine. 2018 Mar;1(1):e1011.

5. Yorimitsu E, Chiba K, Toyama Y,et al.Long-term outcomes of standard discectomy for lumbar disc herniation: a follow-up study of more than 10 year[J]s.Spine (Phila Pa 1976). 2001 Mar 15;26(6):6527.

6. Choi $\mathrm{H}$, Tessier S, Silagi ES,et al.A novel mouse model of intervertebral disc degeneration shows altered cell fate and matrix homeostasis[J].Matrix Biol. 2018 Sep;70:102-122.

7. Oehme D, Goldschlager T, Ghosh P,et al.Cell-Based Therapies Used to Treat Lumbar Degenerative Disc Disease: A Systematic Review of Animal Studies and Human Clinical Trials[J].Stem Cells Int. 2015;2015:946031.

8. Jezierska-Wozniak K, Barczewska M, Habich A,et al.The feasibility of the CD271+ and CD271mesenchymal stromal cell enrichment toward nucleus pulposus-like cells[J].Folia Histochem Cytobiol. 2017;55(3):114-123.

9. Vaudreuil N, Henrikson K, Pohl P,et al.Photopolymerizable biogel scaffold seeded with,mesenchymal stem cells: safety and efficacy evaluation of novel treatment for intervertebral disc degeneration[J].J Orthop Res. 2019 Jun;37(6):1451-1459.

10. Kumar $\mathrm{H}, \mathrm{Ha} \mathrm{DH}$, Lee EJ,et al.Safety and tolerability of intradiscal implantation of combined autologous adipose-derived mesenchymal stem cells and hyaluronic acid in patients with chronic discogenic low back pain: 1-year follow-up of a phase I study[J].Stem Cell Res Ther. 2017 Nov 15;8(1):262.

11. Cui $X$, Liu M, Wang J,et al.Electrospun scaffold containing TGF- $\beta 1$ promotes human mesenchymal stem cell differentiation towards a nucleus pulposus-like phenotype under hypoxia[J].IET Nanobiotechnol. 2015 Apr;9(2):76-84.

12. Kim DH, Kim SH, Heo SJ, et al.Enhanced differentiation of mesenchymal stem cells into NP-like cells via 3D co-culturing with mechanical stimulation[J].J Biosci Bioeng. 2009 Jul;108(1):63-7. 
13. Hudson KD, Bonassar LJ.Hypoxic Expansion of Human Mesenchymal Stem Cells Enhances ThreeDimensional Maturation of Tissue-Engineered Intervertebral Discs[J].Tissue Eng Part A. 2017 Apr;23(7-8):293-300.

14. Naqvi SM, Buckley CT.Differential response of encapsulated nucleus pulposus and bone marrow stem cells in isolation and coculture in alginate and chitosan hydrogels[J].Tissue Eng Part A. 2015 Jan;21(1-2):288-99.

15. Gan Y,Tu B,Li P,et al.Low Magnitude of Compression Enhances Biosynthesis of Mesenchymal Stem Cells towards Nucleus Pulposus Cells via the TRPV4-Dependent Pathway[J].Stem Cells Int. 2018 Apr 17;2018:7061898.

16. Zhang W, Xue K, Gao Y,et al.Systems pharmacology dissection of action mechanisms of Dipsaci Radix for osteoporosis[J].Life Sci. 2019 Oct 15;235:116820.

17. Cheng CF, Chien-Fu Lin J, Tsai FJ,et al.Protective effects and network analysis of natural compounds obtained from Radix dipsaci, Eucommiae cortex, and Rhizoma drynariae against RANKL-induced osteoclastogenesis in vitro[J].J Ethnopharmacol. 2019 Nov 15;244:112074.

18. Wong RW,Rabie AB, Hägg EU.The effect of crude extract from Radix Dipsaci on bone in mice[J].Phytother Res. 2007 Jun;21(6):596-8.

19. Bai L,Zhang HL,Liu JX,et al.Role of Radix Dipsaci in healing process of achilles tendon rupture of rabbit models[J]. Journal of Ankle and Ankle Surgery.2019 Mar ;6(1):5-8.

20. Ke K, Li Q, Yang X,et al.Asperosaponin VI promotes bone marrow stromal cell osteogenic differentiation through the PI3K/AKT signaling pathway in an osteoporosis model[J].Sci Rep. 2016 Oct 19;6:35233.

21. Wang CG, Lou YT, Tong MJ,et a.IAsperosaponin VI promotes angiogenesis and accelerates wound healing in rats via up-regulating HIF-1a/VEGF signalin[J].Acta Pharmacol Sin. 2018 Mar;39(3):393404.

22. Niu Y, Li Y, Huang H,et al.Asperosaponin VI, a saponin component from Dipsacus asper wall, induces osteoblast differentiation through bone morphogenetic protein-2/p38 and extracellular signalregulated kinase 1/2 pathway[J].Phytother Res. 2011 Nov;25(11):1700-6.

23. Cheng gui .Wang, Yi ting. Lou, Min ji .Tong, et al. Asperosaponin VI promotes angiogenesis and accelerates wound healing in rats via up-regulating HIF-1a/VEGF signaling[J]. Acta Pharmacologica Sinica (2018) 39: 393-404.

24. Elsaadany M, Winters K, Adams S,et al.Equiaxial Strain Modulates Adipose-derived Stem Cell Differentiation within 3D Biphasic Scaffolds towards Annulus Fibrosus[J].Sci Rep. 2017 Oct 9;7(1):12868.

25. Jie. Gao, Chun. Zhou, Yadi. Li, et al. Asperosaponin vi promotes progesterone receptor expression in decidual cells via the notch signaling pathway[J]. Fitoterapia 113 (2016) 58-63.

26. Sakai D. Future perspectives of cell-based therapy for intervertebral disc disease[J]. Eur Spine J. 2008 Dec;17 Suppl 4:452-8. 
27. Bian Z, Sun J. Development of a KLD-12 polypeptide/TGF- $\beta 1$-tissue scaffold promoting the differentiation of mesenchymal stem cell into nucleus pulposus-like cells for treatment of intervertebral disc degeneration[J]. Int J Clin Exp Pathol. 2015 Feb 1;8(2):1093-103.

28. Sive $\mathrm{J} I, B a i r d ~ P$, Jeziorsk M,et al. Expression of chondrocyte markers by cells of normal and degenerate intervertebral discs.Spine[J].2002;55(2):91-97.

29. Lee CR1,Sakai D,Nakai T, et al.A phenotypic conparison of intervertebral disc and articular carticular cells in the rat [J]. Eur Spine J, 2007, 16(12): 2174-2185.

30. RisbudMV, Schoepflin ZR, Mwale F, et al. Defining the phenotype of young healthy nucleus pulposus cells: recommendations of the Spine Research Interest Group at the 2014 annual ORS meeting[J].J Orthop Res. 2015 Mar;33(3):283-93.PMID:25411088.

31. Thorpe AA, Binch AL, Creemers LB, Sammon C, et al. Nucleus pulposus phenotypic markers to Determine stem cell differentiation: fact or fiction?[J].Oncotarget, 2016 Jan 19;7(3):2189-200.

32. Thorpe AA, Binch AL, Creemers LB, Sammon C, et al. Nucleus pulposus phenotypic markers to Determine stem cell differentiation: fact or fiction?[J].Oncotarget, 2016 Jan 19;7(3):2189-200.

33. Li GR,Gong LL,Lv YL,et al. Progress in Pharmacological Research of Asperosaponin VI[J]. Chinese Journal of New Drugs and Clinical Sciences,2014,33(7):477-480.

34. Zhou P, Yang X, Yang Z,,et al.Akebia Saponin D Regulates the Metabolome and Intestinal Microbiota in High Fat Diet-Induced Hyperlipidemic Rats[J].Molecules. 2019 Apr 1;24(7). pii: E1268.

35. Yang S, Zhang W, Xuan LL,et al.Akebia Saponin D inhibits the formation of atherosclerosis in $\mathrm{ApoE}_{-/ .}$mice by attenuating oxidative stress-induced apoptosis in endothelial cells[J]. Atherosclerosis. 2019 Jun;285:23-30.

36. Gong LL, Yang S, Liu H,et al.Anti-nociceptive and anti-inflammatory potentials of Akebia saponin D[J].Eur J Pharmacol. 2019 Feb 15;845:85-90.

37. Wang $Y$, Shen J, Yang $X$,et al.Akebia saponin $D$ reverses corticosterone hypersecretion in an Alzheimer's disease rat model[J].Biomed Pharmacother. 2018 Nov;107:219-225.

38. Bai T, Liu F, Zou F,et al.Epidermal Growth Factor Induces Proliferation of Hair Follicle-Derived Mesenchymal Stem Cells Through Epidermal Growth Factor Receptor-Mediated Activation of ERK and AKT Signaling Pathways Associated with Upregulation of Cyclin D1 and Downregulation of p16[J].Stem Cells Dev. 2017 Jan 15;26(2):113-122.

39. Murakami J, Ishii M, Suehiro F,et al.Vascular endothelial growth factor-C induces osteogenic differentiation of human mesenchymal stem cells through the ERK and RUNX2 pathway[J]. Biochem Biophys Res Commun. 2017 Mar 11;484(3):710-718.

40. Zhang Z, Wang J, Chen Y,et al.Activin a promotes myofibroblast differentiation of endometrial mesenchymal stem cells via STAT3-dependent Smad/CTGF pathway[J].Cell Commun Signal. 2019 May 17;17(1):45.

41. Tao Y, Zhou X, Liang C,et al.TGF- $\beta 3$ and IGF-1 synergy ameliorates nucleus pulposus mesenchymal stem cell differentiation towards the nucleus pulposus cell type through MAPK/ERK 
signaling[J].Growth Factors. 2015;33(5-6):326-36.

42. Zhu Y, Gu J, Zhu T,et al.Crosstalk between Smad2/3 and specific isoforms of ERK in TGF- $\beta 1$-induced TIMP-3 expression in rat chondrocytes[J].J Cell Mol Med. 2017 Sep;21(9):1781-1790.

\section{Tables}

Table 1.

\begin{tabular}{|c|c|c|c|c|}
\hline Name & & $5 \rightarrow$ sequence $\rightarrow 3$ & $\begin{array}{l}\text { Product } \\
\text { size }\end{array}$ & $\begin{array}{l}\text { NCBI Reference } \\
\text { Sequences(Ref Seq) }\end{array}$ \\
\hline \multirow[t]{2}{*}{ GAPDH } & Sense & CCAGAACATCATCCCTGCCT & 185 & NM_00125679 \\
\hline & Antisense & ССТGСТTСАССАССТTСТTG & & \\
\hline \multirow[t]{2}{*}{ COL2A1 } & Sense & TCCACGGAAGGCTCCCAGAA & 141 & NM_001844.5 \\
\hline & Antisense & ССTGCTATTGCCCTCTGCCC & & \\
\hline \multirow[t]{2}{*}{ Aggrecan } & Sense & СCTCTGGACAACCAGGTATTAG & 97 & NM_001135 \\
\hline & Antisense & CCAGATGTTTCTCCACTCAGAT & & \\
\hline \multirow[t]{2}{*}{ sox9 } & Sense & GAGCTGAGCAGCGACGTCAT & 130 & NM_000346.4 \\
\hline & Antisense & CGTAGCTGCCCGTGTAGGTG & & \\
\hline \multirow[t]{2}{*}{ KRT19 } & Sense & GGAAGACACACTGGCAGAAA & 112 & NM_002276.5 \\
\hline & Antisense & СTCACTATCAGCTCGCACATC & & \\
\hline \multirow[t]{2}{*}{ PAX1 } & Sense & CCGCTCGCTATGGAGCAGAC & 204 & NM_001257096.1 \\
\hline & Antisense & GGAGCCGGTCTCGTTGTAGC & & \\
\hline
\end{tabular}

\section{Figures}




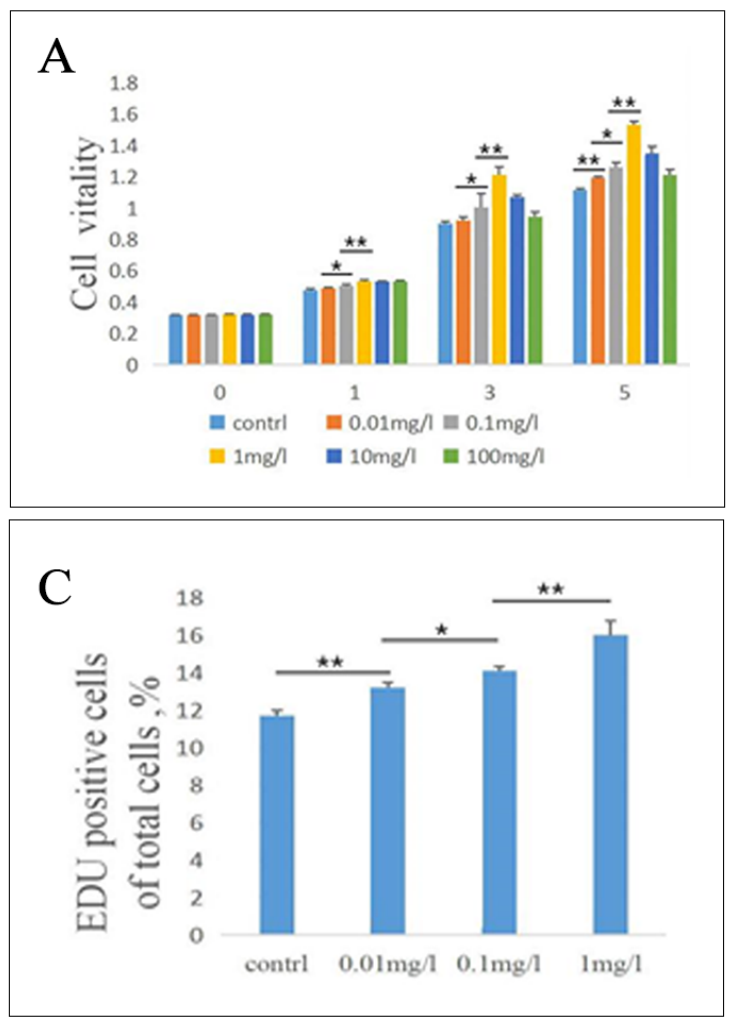

B

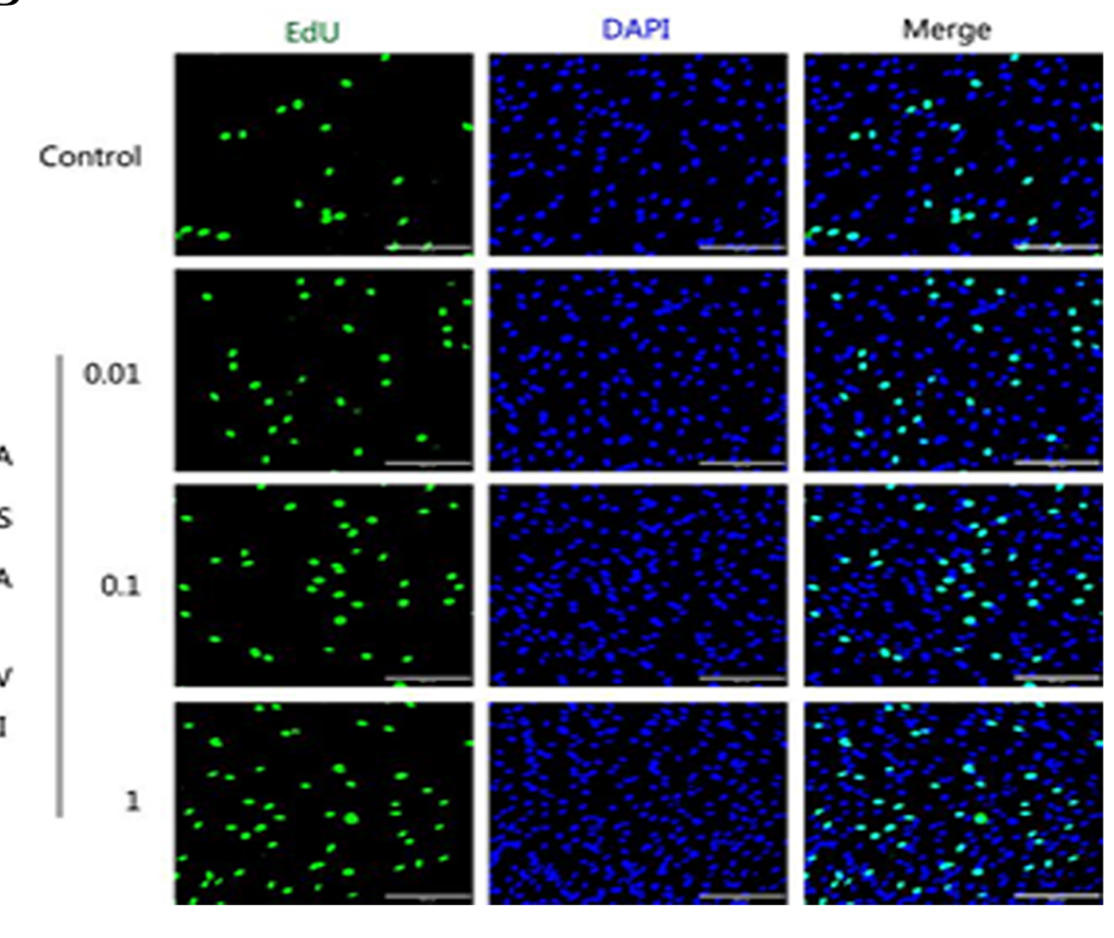

\section{Figure 1}

ASA VI promoted the proliferation of HMSCs. (Figure1A) Cell viability results of HMSCs treated with different concentrations of ASA VI for 1, 3 and 5 days . (Figure1B) EDU staining test of HMSCs after being treated with different concentrations of ASA VI (scale bar: $200 \mu \mathrm{m}$ ). (Figure1C)The relative number of HMSCs stained by EDU in each group. ${ }^{*} p<0.05$ vs the controls, ${ }^{* *} p<0.01$ vs the controls. 

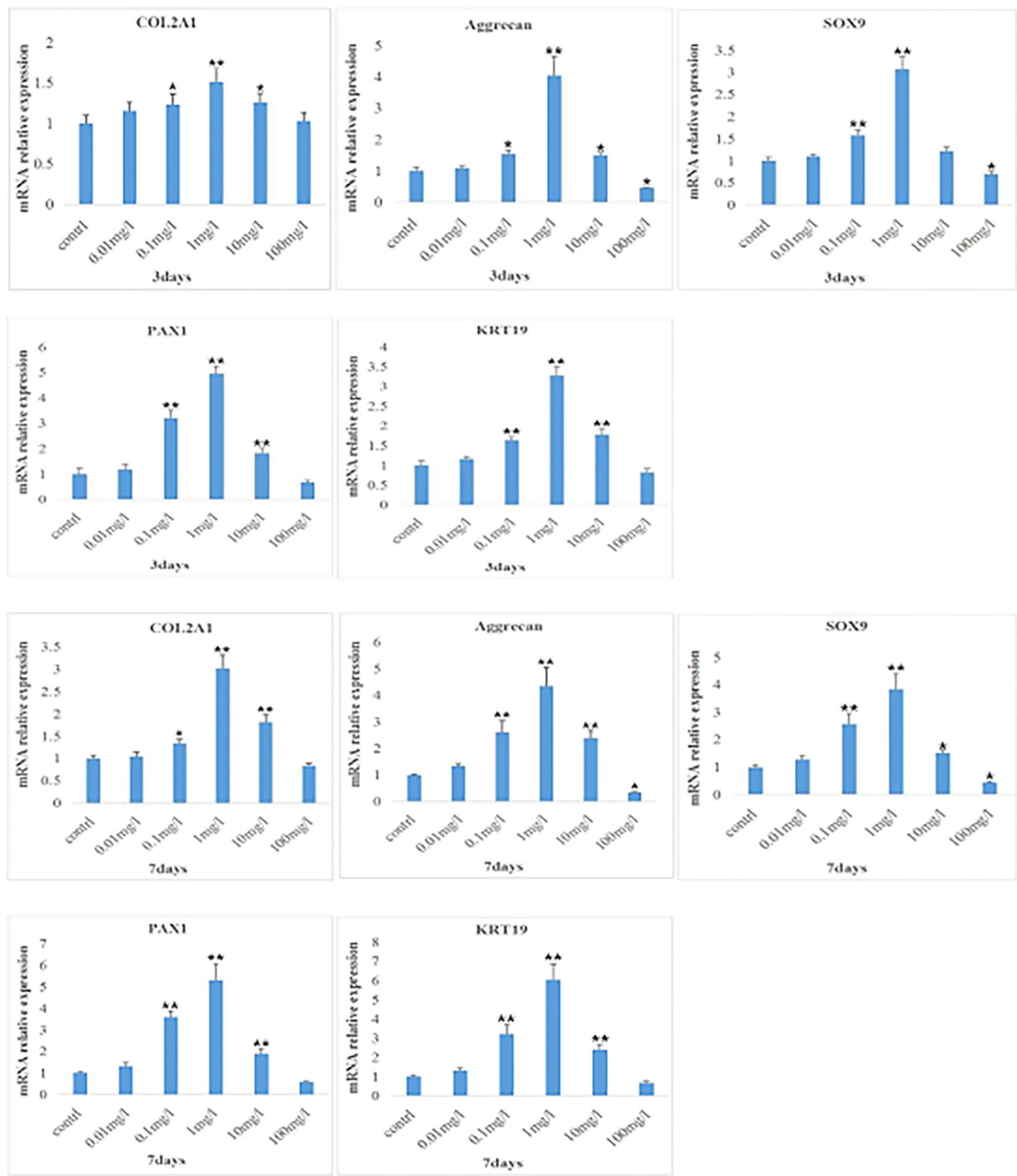

\section{Figure 2}

Effects of different concentrations of ASA VI on gene expression. The expression levels of selected genes were assessed by RT-PCR after cells were treated with different concentrations of ASA VI for 3 and 7 days. ${ }^{*} \mathrm{P}<0.05$ vs the controls, ${ }^{\star \star} \mathrm{p}<0.01$ vs the controls. 


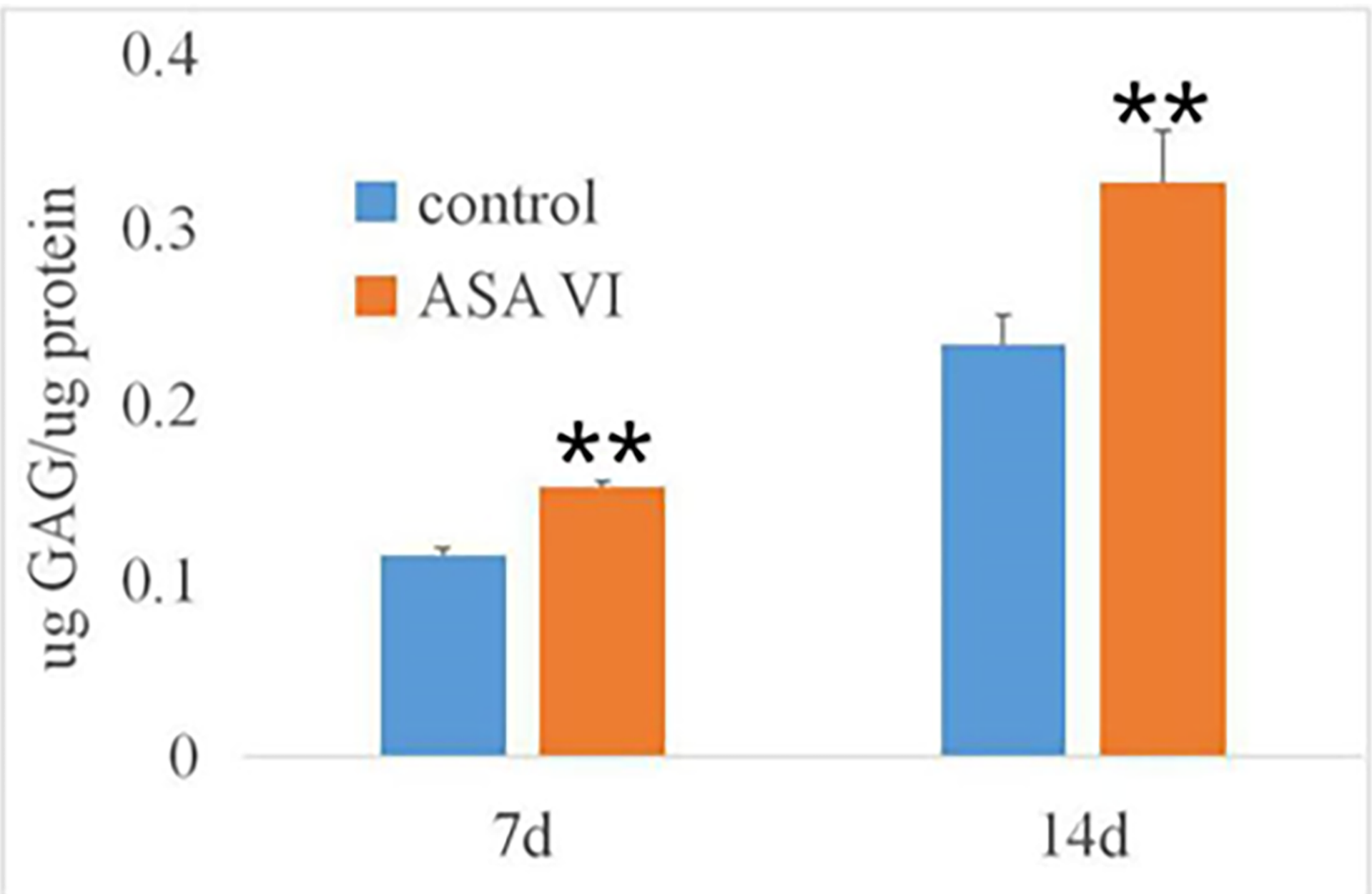

Figure 3

Effect of ASA VI on the amount of GAGs in the culture media. Treatment with ASA VI ( $1 \mathrm{mg} / \mathrm{l})$ showed higher amounts of secreted GAGs in the culture media. ${ }^{\star \star} p<0.01$ vs the controls. 


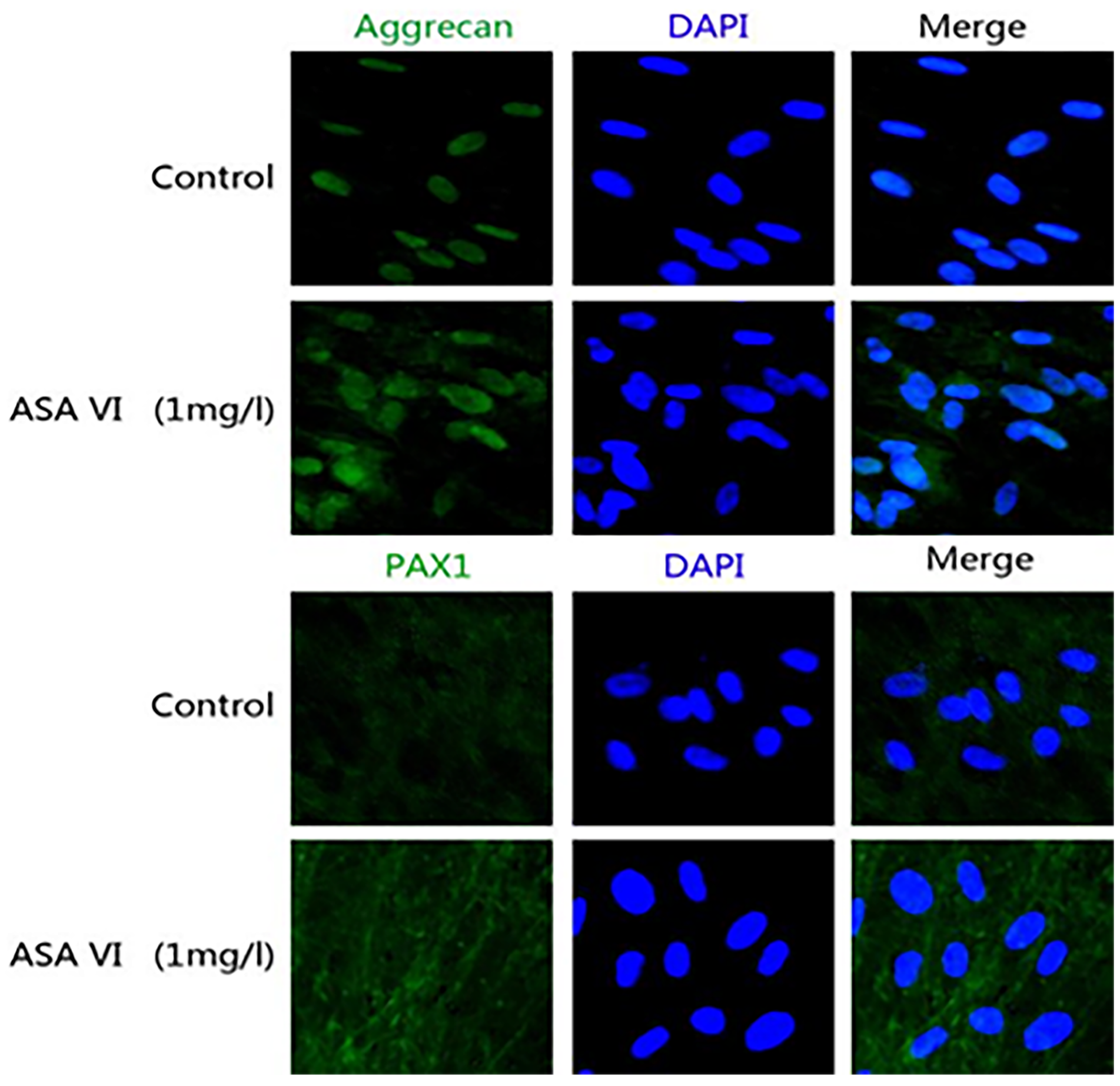

Figure 4

The expression levels of aggrecan and PAX1 genes were verified by immuno-staining. The immunofluorescence signals were stronger (green staining) compared with the controls(scale bar: 200 $\mu \mathrm{m})$. 


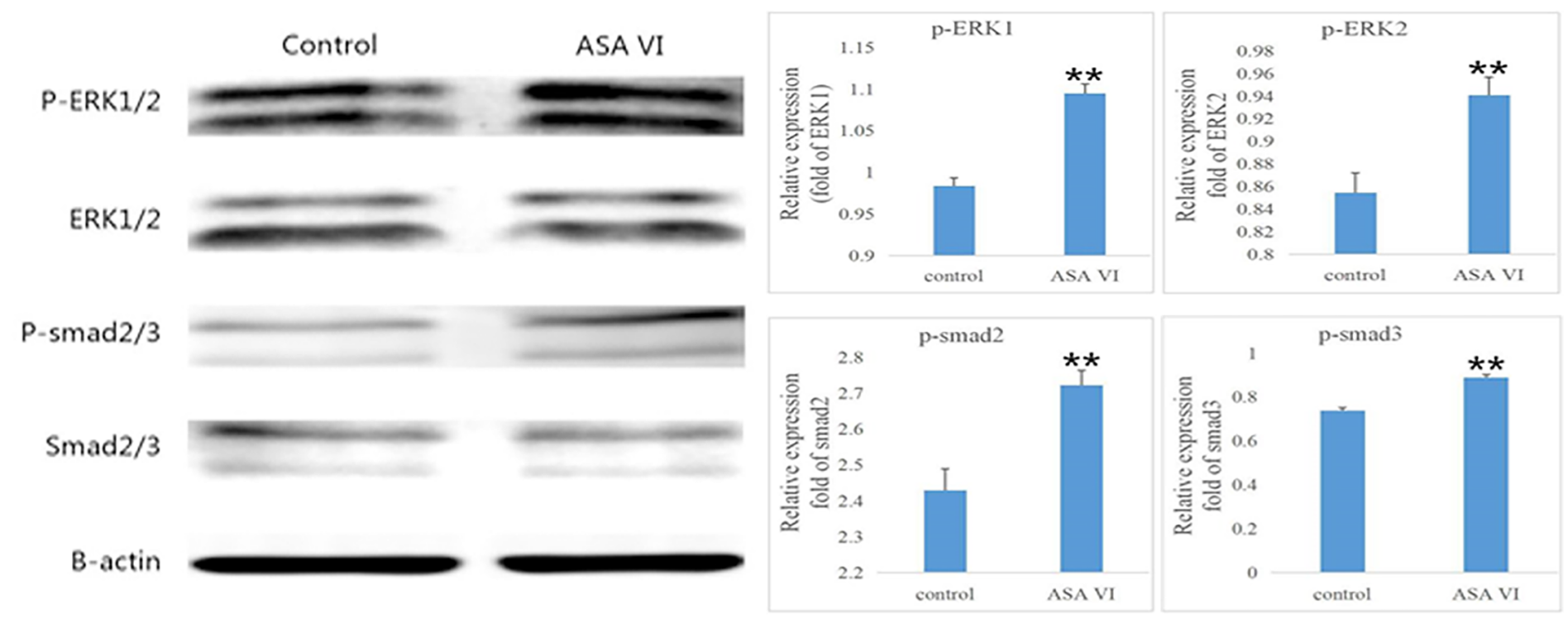

\section{Figure 5}

The effects of ASA VI on the protein expression levels of P-ERK1/2 and P-Smad2/3. Western blot analysis of P-ERK1/2 and P-Smad2/3 expression levels after treatment with ASA VI for 48 hours. P-ERK1/2 and PSmad2/3 were normalized to ERK1/2 and Smad2/3.** $p<0.01$ vs the controls. 